\title{
Seventy years after the end of World War II
}

\author{
Tetsuro Matsuzawa ${ }^{1,2}$
}

Published online: 19 March 2015

(C) Japan Monkey Centre and Springer Japan 2015

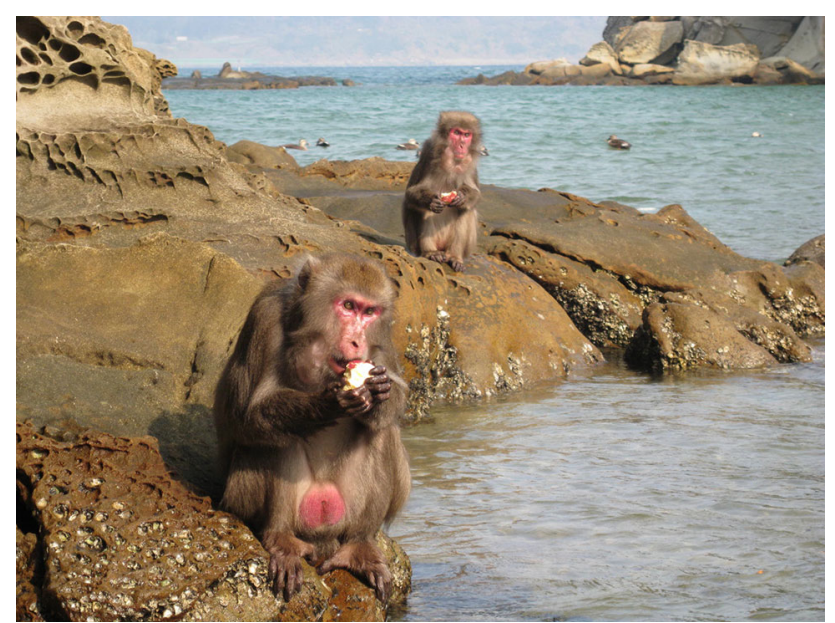

Photo by Tetsuro Matsuzawa

There are no species of monkeys or apes native to either North America or Europe. In contrast, Japan has its own species of monkey: the Japanese macaque. Thus, in Japan, the discipline of Primatology grew out of a curiosity about this native monkey. Primatology in Japan began in 1948. The late Kinji Imanishi (1902-1992) and his two undergraduate students from Kyoto University set out for Koshima Island to observe wild monkeys. At the time, Imanishi was 46 years old, and an unpaid lecturer at Kyoto University. The Department of Zoology had full-time, salaried Professors and Associate professors, yet the young

Tetsuro Matsuzawa

matsuzawa.tetsuro.8w@kyoto-u.ac.jp

Japan Monkey Centre, Inuyama, Japan

2 Kyoto University, Inuyama, Japan undergraduates chose to follow this impoverished and young lecturer. Why did they follow Imanishi? Because they found the question that he had formulated absolutely fascinating: he aimed to discover the evolutionary origins of human society by observing monkeys. It was initiated a mere 3 years after the end of the Second World War. Japan had surrendered on August 15th 1945: about a week after two atomic bombs devastated Hiroshima and Nagasaki. During the period 1948-1955, young students belonging to Kyoto University spent a total of more than 1500 days observing populations of wild monkeys, across 19 different research sites. They made many interesting discoveries. First, that the Japanese macaque has a defined breeding season. Second, they observed that all the solitary individuals were male. This revealed that it is the female monkeys who stay within their natal community, producing a matrilineal lineage: grandmother-mother-daughter. Third, they observed a dominance hierarchy among the males; fourth, a rich vocal repertoire used for communication; and fifth, animal proto-culture in the group-specific behaviors of sweet-potato washing and wheat-mining (Matsuzawa and McGrew 2007, Current Biology). Masao Kawai (born in 1924, age 91, he was Editor-in-Chief of Primates for many years), is the only surviving student of the pioneering Imanishi. He shared with me what secretly motivated the students. They wanted to discover the origins of the dark aspects of human nature, for example, violence and cruelty. Japan invaded to the neighboring countries during the war. No less than a third of Kawai's generation perished during the war: it was kill or be killed. Some took up arms and killed men on the opposing side, while others fell on the battlefield. A recent paper (Wilson et al. 2014, Nature), work involving the collaboration of 28 field-sites in Africa including the Bossou-Nimba site (my research 
site), reported 152 cases in which chimpanzees had been observed to kill other chimpanzees. Primatologists all over the world are striving to better understand our evolutionary neighbors. However, it might also be necessary to always look at human behavior in the real-world and reflect on our own nature. We have the power of imagination that is uniquely human; our ability to travel enormous distances in time and space in our mind. Human-beings might be the only species on Earth with the capacity to imagine the past even before their birth, and think ahead to a future beyond even their own death. This year is the 70th anniversary of the end of the Second World War. Through scientific research we should come to know more about the nature of nonhuman primates, but also of the primate called the human: ourselves.

Tetsuro Matsuzawa

Editor-in-Chief, Primates

General Director, Japan Monkey Centre

Professor, Kyoto University

President, International Primatological Society 